\title{
O SIGNIFICADO DO DIAGNÓSTICO DO CÂNCER DE MAMA PARA A MULHER
}

\author{
The meaning of diagnostic of breast cancer for woman. \\ El significado del diagnóstico del cancer de mamma para la \\ mujer.
}

lliana Maria de Almeida Araújo

Ana Fátima Carvalho Fernandes²

\section{RESUMO}

Objetivamos compreender o significado do diagnóstico do câncer de mama para a mulher. Na busca dessa compreensão, optamos por um referencial teórico, fundamentado nas interações e vivência do indivíduo à luz do interacionismo simbólico. Utilizamos como instrumento a entrevista semi-estruturada, com oito mulheres com câncer de mama. A análise das narrativas permitiu a identificação de unidades temáticas agrupadas em duas grandes categorias: 0 impacto do diagnóstico de câncer de mama e 0 enfrentamento do câncer de mama. 0 estudo do tema possibilitou compreender o impacto do diagnóstico do câncer de mama, quando o mesmo leva a sentimentos de medo da morte e de o câncer ser uma doença irremediável. Na subcategoria Por que comigo?, as mulheres revelaram o seu medo de perder sua identidade como mulheres através dos sentimentos de medo da mutilação e dependência. Pelo enfrentamento do câncer de mama, a mulher busca construir a sua nova identidade como alguém que tem câncer.

Palavras-chave: Neoplasias Mamárias. Saúde da Mulher. Enfermagem.

\begin{abstract}
We objectify to understand the meaning of the diagnosis of the cancer of breast for the woman. In the search of this understanding we opt to a theoretical referential, based on the interactions and experience of the individual to the light of the symbolic interactions. We use as instrument the half-structuralized interview, with 8 women with breast cancer. The analysis of the narratives allowed the identification of grouped thematic units in two great categories: The impact of the diagnosis of breast cancer and the confrontation of the breast cancer. From the study of the subject, it was possible to understand the impact of the diagnosis of the breast cancer, same as it takes the feelings of fear of the death and the cancer to be an irremediable illness. In the sub-category Why with me? The women had disclosed its fear to lose its identity as women, through the feelings of fear of the mutilation and dependence. The confrontation of the breast cancer makes the woman search for its new identity as somebody that has cancer
\end{abstract}

Keywords: Breast Neoplasms. Women's health. Nursing.

\section{Resumen}

Nosotros apuntamos a entender el significado del diagnostico del cáncer de mama para la mujer. En la búsqueda de esa comprensión nosotros optamos para un referencial teórico, basado en las interacciones y existencia del individuo a la luz de Interacionismo Simbólico. Nosotros usamos como el instrumento la entrevista semi-estructurada dónde todas las deposiciones de las ocho mujeres eran estrictamente anotadas como la forma de garantizar la veracidad de la información. El análisis de las narrativas permitió la identificación de unidades temáticas contenida en dos grandes categorías: El impacto del diagnóstico de cáncer del mama y el enfrentamiento del cáncer de mama. El estudio del tema hizo posible la comprensión el impacto de la diagnosis del cáncer de pecho, cuando igual él toma las sensaciones del miedo de la muerte y del cáncer para ser una enfermedad irremediable. ¿En la subcategoría porqué conmigo? Las mujeres habían divulgado su miedo para perder su identidad como mujeres, con las sensaciones del miedo de la mutilación y de la dependencia. La confrontación del cáncer de pecho la mujer al buscar construir su nueva identidad como alguien que tiene cáncer.

Palabras-claves: Neoplasias de la Mama. Salud de la mujer. Enfermería. 


\section{INTRODUÇÃO}

0 câncer de mama é motivo de grande temor na sociedade em geral e principalmente nas mulheres, em decorrência do elevado índice de morbimortalidade e de mutilação, com conseqüente comprometimento da auto-estima e do desenvolvimento social de quem é por ele acometido. Ademais, interfere sobremaneira nas relações sociais, pessoais, profissionais e afetivas.

$\mathrm{Na}$ literatura atual, segundo as evidências, este tipo de câncer situa-se entre as primeiras causas de morte por câncer nas mulheres. Causa, portanto, profundo impacto psicológico na percepção da sexualidade, na imagem pessoal e auto-estima, de maneira muito mais marcante do que qualquer outro câncer ${ }^{1 .}$

Para o Ministério da Saúde, no Brasil em 2008, a estimativa da incidência de câncer de mama no país, referente às mulheres, está em torno de 49.400 novos casos, ou seja, uma taxa bruta de 53,93\%, perdendo apenas para o câncer de pele nãomelanoma. Conforme as estatísticas, o câncer de mama continua na vanguarda como causa mortis em mulheres, seguido pelo câncer de pulmão, cólon e reto, colo do útero e estômago, e constitui a segunda neoplasia maligna mais incidente no mundo civilizado ${ }^{2}$.

0 câncer de mama tem se tornado sério problema de saúde pública, pois vêm aumentando tanto a incidência de casos novos como o número de óbitos em mulheres de todas as idades. Como justificativa para esta situação, sobressaem a educação deficiente das mulheres em relação aos fatores de risco e a demora em procurar atendimento, seja por falta de acesso, seja por medo ou negação da doença ${ }^{4}$. Esta afirmativa revela não apenas o problema patológico em si, mas também a fragilidade da mulher que se vê diante de uma doença grave, mortal. Diante desta doença, a mulher passa por completa mudança em suas relações sociais, familiares e com ela mesma. Requer, portanto, além de uma assistência médico-hospitalar, assistência humanizada, capaz de vê-la como pessoa que sofre, mas que não perdeu sua essência.

De modo geral, a aversão ao câncer de mama por parte das mulheres deve-se aos seus efeitos biopsicossociais, os quais a afetam profunda e significativamente. Em face do diagnóstico, a mulher passa por crises de instabilidade, marcadas por medos, frustrações, conflitos e insegurança. Esse sofrimento está associado ao caráter incurável e à idéia de possível morte.

A confirmação do diagnóstico causa impacto psicossocial tanto na paciente quanto em seus familiares. Tal impacto requer uma rede social de apoio, com vistas a facilitar o reconhecimento e a aceitação da doença, e encontrar a melhor forma de adaptação ${ }^{5}$.

Ocorrerão alterações no cotidiano dessa mulher, mas estas alterações não poderão ser desprezadas, pois é nesse momento que se inicia uma etapa definitiva na sua vida e ela precisa ser informada sobre como deve prosseguir a partir daquele agravo.
É indispensável apóia-la e encorajá-la a superar conflitos pessoais e sociais possíveis de surgir.

Atualmente a mulher desempenha inúmeros papéis, como mãe, esposa, trabalhadora, chefe de família e cidadã. Neste universo, são muitos obstáculos ao desempenho dos seus papéis, principalmente quando essa mesma mulher adoece. Nesta situação particular, um suporte emocional especializado deverá ser sempre oferecido, pois, muitas vezes, o estresse decorrente do diagnóstico dificulta a absorção racional de todas as informações dadas ${ }^{5}$.

Outro aspecto importante é que o câncer de mama é considerado uma doença estigmatizante por todos, e particularmente pela pessoa que é acometida, na qual acarreta mudanças no comportamento. Tomada por estes sentimentos, a pessoa tende a se isolar do seu convívio social e familiar, passando por uma perda de identidade na sua rede social de apoio. Segundo esses aspectos, as neoplasias malignas causam não apenas sofrimento físico, como também sérias conseqüências psíquicas e sociais. Baseados nisso, os enfermeiros devem buscar a assistência de enfermagem holística e humanizada para a paciente e sua família ${ }^{1}$.

Ante o exposto, a nosso ver, é extremamente difícil passar por uma doença como o câncer sem algum tipo de seqüela, seja física, psíquica ou social. E justifica-se a importância de conhecer quais os problemas vividos pelas mulheres em face do diagnóstico de câncer de mama e quais os modos de enfrentamento utilizados. Nossa finalidade é embasarmos a assistência de enfermagem integralizadora e humanizada e criarmos uma rede social de apoio, na tentativa de minimizar o sofrimento e reabilitar essas mulheres para o convívio social e familiar ${ }^{4}$.Após as consideraç̃̃es feitas, o objetivo proposto é: compreender o impacto do diagnóstico de câncer mama para a mulher.

\section{METODOLOGIA}

Entender o enfrentamento do câncer pela mulher é algo bastante complexo. Pensamos, então, em uma fundamentação teórica que permitisse 0 aprofundamento da análise dos significados, e optamos por uma abordagem interativa, comunicativa, que interpretasse o desvelamento do significado do câncer de mama pela própria mulher dentro do seu contexto social, comportamental e ambiental.

Optamos pelo interacionismo simbólico, pois partimos do pressuposto de que esta abordagem favorece a apresentação descritiva pelas próprias mulheres de como elas vêem os objetos, de como elas agem em diferentes situações e de como elas se referem aos objetos em suas conversas com membros do seu próprio grupo. Trata-se de uma teoria na qual o significado é o conceito central, no qual as proposições teóricas ocorrem a partir da interação das pessoas dentro da estrutura social, as ações humanas definindo e participando do mundo; ou seja, o interacionismo simbólico é uma perspectiva cujas raízes repousam em pressupostos da psicologia social ${ }^{6}$. 
O foco da abordagem qualitativa busca uma melhor relação de compreensão do significado e da intencionalidade como inerentes às relações humanas e suas estruturas sociais. Mas as estruturas sociais são construções humanas significativas, por isso a grande abertura às transformações pelos próprios homens na sociedade e, ainda, a capacidade de influenciar os comportamentos dos sujeitos envolvidos em seus atos sociais em estudo. 0 interacionismo simbólico constitui-se em uma perspectiva sobre o papel do ser humano em sociedade, englobando comunicação, linguagem e interação.

0 significado é elaborado no processo de interação de duas pessoas. Dessa forma, o significado de determinada coisa para uma pessoa cresce de acordo com a forma pela qual as outras pessoas agem em relação a essa coisa. 0 significado é formado dentro e através de atividades definidoras das pessoas quando interagem ${ }^{7}$.

Nesse contexto, o estudo foi realizado dentro de uma abordagem qualitativa, objetivando a compreensão dos resultados a partir das narrativas do cotidiano e dos objetivos propostos. Esta abordagem aprofunda-se no mundo dos significados das ações e relações humanas, um lado não perceptível e não captável em números estatísticos.

Elegemos o estudo qualitativo por considerarmos que esta abordagem permite uma aproximação do sujeito com o objeto, e ajuda a descrever e analisar a interação de variáveis envolvidas, compreendendo e classificando as experiências sociais vividas pelos sujeitos. Este estudo foi desenvolvido em um hospital de referência no tratamento do câncer, no município de Fortaleza, instituição vinculada à rede de serviços públicos do Estado do Ceará.

Como sujeitos da amostra fizeram parte oito mulheres acompanhadas e tratadas no serviço nos meses de maio a julho de 2004 e que estavam incluídas nos seguintes critérios: diagnóstico confirmado de câncer de mama; aceitassem participar da pesquisa mediante Termo de Consentimento Livre e Esclarecido e, principalmente, tivessem consciência absoluta de estarem com câncer de mama. Convém ressaltar que 0 tamanho da amostra foi limitado pela saturação de informações, ou seja, à medida que se foi descobrindo o fenômeno e passamos a compreendê-lo em todas as suas dimensões, a coleta dos dados foi encerrada.

Na perspectiva interacionista, vários procedimentos foram utilizados para coletar dados, considerando os processos de exploração e inspeção. Neste estudo, utilizou-se como instrumento para coleta de dados a entrevista semiestruturada. As informações foram obtidas por meio de um roteiro de entrevista composto de uma lista de pontos ou tópicos previamente estabelecidos de acordo com a problemática central a ser seguida.

A entrevista semi-estruturada é um instrumento que valoriza a presença do investigador. Propicia todas as possibilidades para o informante se sentir seguro e livre para oferecer espontaneamente os dados e enriquecer a investigação. Após aprovação do Projeto pelo Comitê de Ética e Pesquisa (COMEPE) da Universidade Federal do Ceará, segundo a resolução 196/96, a coleta de dados foi iniciada.

Procedemos à organização dos dados com base na análise dos discursos dos sujeitos envolvidos na investigação. Esse método permite a inferência de conhecimentos relativos às condições de produção, inferência esta que recorre a indicadores quantitativos ou não ${ }^{8}$. Para garantir 0 anonimato das mulheres participantes do estudo, atribuímos a cada uma um nome fictício deflores.

\section{DISCUSSÃO DOS RESULTADOS}

Os resultados identificaram as características da clientela, que se mostrou bastante heterogênea. Quanto à faixa etária, 0 intervalo de idades predominou entre 43 e 59 anos. Apenas uma participante tinha 25 anos de idade. Sete das mulheres participantes residiam na capital, embora nesse grupo algumas fossem naturais do interior do Estado. Uma mulher era procedente de uma cidade do interior do Estado. Entre as participantes, uma era solteira e sem filhos, enquanto as demais eram casadas e tinham em média de dois a cinco filhos.

Todas as mulheres trabalhavam de alguma forma para ajudar no sustento da família ou para exercer sua profissão; duas das participantes eram graduadas, das quais uma professora e a outra funcionária pública. As demais possuíam níveis escolares baixos e exerciam ocupações como lavadeira, costureira, dona de casa. A renda familiar mensal oscilou de $\mathrm{R} \$ 200,00$ a $\mathrm{R} \$$ 700,00 . Algumas mulheres respondiam financeiramente pelo sustento de suas casas.

Com base no assunto em estudo, trabalhamos com unidades temáticas agrupadas em duas categorias: 0 impacto do diagnóstico de câncer de mama e 0 enfrentamento do câncer de mama. Ressaltamos que as categorias estão centradas nos significados de como a mulher vivencia o impacto da descoberta do câncer de mama. Para a melhor compreensão dessas categorias temáticas, as mesmas foram divididas em subcategorias, quais sejam: Eagora?Tenho câncer de mamal; Por que comigo?; Não me reconheço no espelho; Sentindo as dificuldades na pele; Enfrentando o medo da morte; Nem tudo está perdido.

\section{O IMPACTO DO DIAGNÓSTICO DO CÂNCER DE MAMA}

A comprovação da realidade de estar com uma doença grave e estigmatizada como o câncer de mama é a primeira etapa vivenciada e percebida pela mulher. As evidências iniciais, e depois a confirmação de estar doente, levam a mulher a vivenciar contraditórios sentimentos e a adotar comportamentos e atitudes ante a doença em suas relações sociais, familiares e pessoais. 0 diagnóstico de câncer mamário traz consigo traumas psicológicos, perda da auto-estima, sentimento de culpa e de fracasso ${ }^{1}$. 
Para uma pessoa, os significados de determinado objeto surgem fundamentalmente da forma pela qual são definidos por essa pessoa, como resultante das interações ao longo da vida. Desse modo, podemos afirmar que a compreensão das mulheres e sua percepção em face do diagnóstico do câncer de mama sofrem as influências das interações onde se formam, transformam e sustentam os conceitos que elas têm delas mesmas e do câncer de mama ${ }^{6}$. Conforme esses argumentos, 0 impacto do diagnóstico de câncer de mama é representado por duas subcategorias.

\section{E agora? Tenho câncer de mamal}

Ao se manifestarem os primeiros sinais, a mulher já desconfia de um possível diagnóstico de câncer de mama. Nessa fase, os significados que ela atribui a respeito e o conhecimento prévio da doença levam-na a suspeitar de que há algo diferente em seu corpo. Reconhecendo o surgimento dos primeiros sinais ou sintomas da manifestação da doença, a mulher percebe que algo não está bem.

[...] Quando eu comecei a sentir as dores, pedi para minha sobrinha olhar o que era, ela disse: tia parece um caroço, na hora eu gelei, fiquei branca.(Margarida).

A presença de possíveis sinais de câncer de mama, tais como alterações na pele, dor, aparecimento de tumor ou eventual piora do quadro, ou mesmo a descoberta ocasional de um nódulo até então desconhecido, leva as mulheres a ficarem intrigadas.

Eu senti o nódulo na minha mama esquerda em março de 2002, procurei logo o médico, que me encaminhou para cá, chegando aqui foi realizada a biópsia, aí deu um câncer. (Margarida).

Muitas vezes vivenciar o câncer pode ser indícios de morte. Mas pode ser também o momento de se reformular a vida. A mulher vivencia a incerteza e insegurança quanto ao que vai acontecer, ainda sob efeito do impacto do diagnóstico. Suas atitudes e comportamentos vão depender do significado por ela atribuído ao câncer, das suas relações e interações sociais e, ainda, dos papéis por ela desempenhados. É muito importante para a tomada de atitudes a relação que se desenvolverá com o profissional de saúde, pois a mulher se encontrará vulnerável e dependente. Naquele momento, ela necessita de uma relação de confiança com vistas a sua melhor aceitação, adaptação e tomada de decisões.

0 impacto do diagnóstico de câncer de mama é influenciado pelo contexto sociocultural no qual o indivíduo está inserido, por interferir no seu comportamento e em suas atitudes quando da descoberta. As mulheres têm suas próprias crenças a respeito do câncer de mama. Tais significados são formados ao longo da vida, de modo especial em suas interações familiares e sociais ${ }^{1}$.
No entanto, o comportamento absorvido surge em torno de problemas. Ele representa uma iniição temporária da ação, na qual, às vezes, tentamos prever o futuro. Assim, ao receber o diagnóstico, a mulher traça conjecturas a respeito de todo 0 caminho de dificuldades a ser percorrido a partir da descoberta do câncer de mama ${ }^{9}$. Corroborando a afirmação, as depoentes do estudo deixaram claro em suas declarações como foi difíicil receber o diagnóstico.

O médico contou de uma vez. Ele disse: a senhora tem câncer de mama, vai fazer quimioterapia, seu cabelo vai cair, a senhora vai perder o peito e pode morrer. (Dália)

Essas mulheres tentam referir as dificuldades de conviver com um momento muito complexo. Vivencia-se o real sentimento de que a vida está acabando, a mutilação é certa e o futuro é uma incógnita. Diante dos fatos, instala-se uma reação depressiva.

[...] Quando recebi o resultado pensei: e agora, como vai ser? O que eu vou fazer? Tenho chances? Já vi na televisão histórias de mulheres que se curaram, será que eu posso? (Tulipa)

Dessa forma, o caráter do trauma provocado pelo conhecimento do diagnóstico de câncer de mama e pela mastectomia depende do valor pessoal a ele atribuído, assim como da sobrecarga da pessoa e da resistência às possibilidades de integração e elaboração.Isso contribui para a elaboração de diferentes respostas à doença ${ }^{10}$.

Esse aspecto deve ser reforçado, pois a maioria das mulheres vê o câncer como algo irremediável. É como se tudo aquilo que o indivíduo fizesse após o diagnóstico fosse em vão. Ela se sente impotente para reverter o quadro de enfermidade já instalado. Mesmo quando se trata de bons prognósticos, ainda é forte a crença de que câncer e morte são sinônimos ${ }^{11}$.

\section{Por que comigo?}

De um modo geral, as pessoas não estão preparadas para perder a identidade, o simbolismo como seres humanos saudáveis, com seus diversos papéis sociais. Descobrir-se com uma doença grave gera angústia, tristeza, desesperança. Gera também culpa, e a pessoa tenta entender os acontecimentos, para saber onde errou e o que levou ao acometimento por essa injúria. Surgem perguntas irrespondíveis e incertezas que devem ser enfrentadas junto com a doença. Nesse momento, a mulher se questiona: por que comigo?

[...] Sempre pensei muito em não deixar faltar nada para a minha familia. Por isso, demorei a procuraro médico, porque não queria deixar de trabalhar. $E$ agora, se eu morrer? A gente também tem que 
pensar em si mesma, se não... olha só o que acontece, a gente corre tanto para sobreviver que se esquece de viver a própria vida, é o que está acontecendo comigo agora (Gardênia).

0 pudor, a vergonha, 0 isolamento sempre fizeram parte do enfrentamento do câncer nos anos 40 do século XX. Esses sentimentos afetam particularmente as mulheres com câncer de mama, ameaçadas pela mutilação de um dos principais símbolos de sua feminilidade ${ }^{9}$.

Tratando-se da dinâmica familiar, a vivência do câncer é mais traumática para os pacientes e suas famílias do que outras formas de doenças. As pacientes experimentam uma alteração de papéis familiares e sociais e por longo tempo podem permanecer doentes, desamparadas e dependentes. Para elas, dificilmente existe outra doença que gere tantos sentimentos negativos ${ }^{11}$. 0 depoimento de Magnólia ilustra de modo significativo a afirmação do autor.

[...] Senti o nódulo há mais ou menos dois anos. Procurei o médico e ele pediu uma mamografia. Com medo do exame e por causa do trabalho, que eu não podia perder, deixei para lá, não procurei mais. No ano passado, comecei a sentir dores fortes no peito. Eu dizia que era coração, coluna, qualquer coisa, menos câncer, mas todos já notavam o caroço por baixo da blusa (Magnólia).

Conforme entendemos, a negação da doença também induz a mulher a se sentir amedrontada e culpada, consciente de que a fuga complica ainda mais a situação. Segundo observamos em seu íntimo, a mulher já desconfiava da doença e, por isso, pelo significado do câncer para ela, buscou sublimar, não deu a devida importância ao problema e atualmente se culpa, acha que tudo poderia ter sido diferente. Toda essa experiência vivenciada resulta em aprendizagem para o indivíduo. As situações que a vida nos apresenta diariamente exigem de nós respostas para enfrentá-las. A doença faz parte do nosso processo contínuo de aprendizado ${ }^{12}$.

0 ser humano tem de enfrentar as situações em que é chamado para agir, acertando o significado das ações dos outros e mapeando sua própria linha de ação à luz de tal interpretação. Ele tem de construir sua ação ${ }^{7}$.

A análise de todos esses depoimentos deixou claro que as mulheres do estudo sentiram o impacto do diagnóstico, não só pela gravidade da doença, pois de certa forma elas já previam que poderia acontecer.

Para o interacionismo simbólico, essa interpretação da situação é fruto das vivências e experiências ao longo da vida. A ação humana é construída enfrentando o mundo ao invés de simplesmente ser liberada de uma estrutura psicológica ${ }^{6}$.

Alguns comportamentos evidenciam a maneira como as pessoas vivem. Até o surgimento do câncer, muitas mulheres se orientam por uma forma de criação e educação. De certo modo, as mulheres são educadas de maneira repressora, voltada para a família, sendo servis e complacentes, e até negligenciando a própria saúde em alguns momentos ${ }^{12}$.

\section{O ENFRENTAMENTO DO CÂNCER DE MAMA}

A mulher com câncer de mama convive com sentimentos de incerteza e insegurança, desde a descoberta do nódulo à confirmação do diagnóstico. Além disso, o impacto é uma vivência demasiadamente significativa e influencia todo 0 processo até a reabilitação do doente. No enfrentamento dessa situação, a mulher tenta se conhecer e se reconhecer nesta nova condição e imagem, na qual se incluem as dificuldades advindas após a doença. Começa, então, a buscar razões para prosseguir nessa nova vida, como uma nova mulher.

\section{Não me reconheço no espelho}

Mastectomizada, a mulher experimenta o sentimento de ser uma pessoa incompleta, marginalizada. Nesse momento, os acontecimentos ao longo da sua vida influenciam positiva ou negativamente na aceitação da nova imagem. A mama feminina representa todo um simbolismo e todo um conceito que a mulher faz de si mesma. Ela é a comprovação da feminilidade, da sexualidade. Sua perda, portanto, é algo devastador, uma castração.

As mulheres Dália e Tulipa referem dificuldades na convivência com o câncer de mama e assim se expressaram:

\section{[...] Já fico triste com a minha aparência, imagine se eu tivesse tirado tudo" (Dália).}

[...] Sentio nódulo mais ou menos em novembro do ano passado. Procurei o médico e ele me encaminhou para Fortaleza. Sempre desconfieique fosse câncer, mas a médica não me disse que eu iria tirar o peito. Por isso não contei nada para ninguém, nem para a família. Só na véspera da cirurgia o médico falou que eu ia tirar o peito. Foi um desespero para mim e minha família, que só aí ficou sabendo (Tulipa)

A imagem corporal é formada de conceitos que o indivíduo tem do seu próprio corpo, não apenas uma imagem física, mas também psicológica, social e cultural. Do ponto de vista da interação simbólica, os seres humanos devem ter uma composição que combine a natureza da interação social. 0 ser humano é visto como um organismo que não somente responde aos outros em nível não simbólico como faz indicações para outros e interpreta suas indicações. Para os interacionistas, 0 ser humano pode ser objeto de sua própria ação. Assim, ele pode se reconhecer como um homem ou uma mulher que age em relação a si próprio e se guia em sua ação ${ }^{10}$.

Muitas mulheres aceitam a perda da mama. Mas esta aceitação decorre do fato de ser inevitável, como o único caminho para a cura tão esperada, ou seja, se livrar do mal. Para outras, no entanto, a frustração após a cirurgia é traumática.

Muitas vezes quando a imagem corporal vai se alterando gradativamente como um processo de envelhecimento, o corpo 
se modifica por etapas, sem provocar interferências tão profundas na personalidade. Na mastectomia, a imagem da mulher é modificada bruscamente, sem tempo para adaptação e como conseqüência de uma doença grave. A nova situação se assemelha a uma mutilação, chega e subtrai repentinamente algo importante e insubstituível ${ }^{13}$.

\section{Sentindo as dificuldades na pele}

Diante das limitações físicas, a mulher também passa a enfrentar as limitações sociais, como a mudança de papéis, ou abre mão das atividades rotineiras, tais como o trabalho, 0 cuidado com os filhos e a casa. As relações pessoais e de amizade também são comprometidas, e em algumas situações instala-se um isolamento social.

Variadas preocupações vêm à tona. Elas temem ser um incômodo, depender dos outros, não atrapalhar. Nessa nova realidade, é preciso haver readaptação das atividades rotineiras. No primeiro momento, a mulher se sente frágil e inútil tanto em relação às tarefas mais simples até às mais complexas, como prover o próprio sustento e da família. Ocorre profundo sofrimento moral e psicológico, mais do que o físico. Mas a mulher deve ser estimulada a não desistir e buscar saídas para uma melhor adaptação a esta nova condição.

As dificuldades não são apenas essa doença, mas tudo, o tratamento, ficar sem poder trabalhar para se manter, não é a mesma coisa. (Tulipa)

0 comportamento social das mulheres com câncer de mama é afetado e provoca restrições na vida social, como uma disfunção de papéis. Em decorrência da doença, elas deixam seus empregos, restringem suas atividades domésticas e sociais, e isso contribui para acelerar o comportamento depressivo e o isolamento social, pois as mulheres, por não desempenharem tarefas que outrora eram suas, se sentem inúteis ${ }^{14}$.

Se a mulher é parte da força de trabalho que provém o sustento da família, a situação pode se tornar muito complicada e a ferida moral é maior, pois às vezes elas passam a depender dos outros até para se alimentar.

[...] 0 meu cabelo caiu todo, deixei de trabalhar, minha aposentadoria foi negada e hoje estou morando com uma tia, por causa das condições. Mas as condições dela também não são boas. (Rosa)

\section{Enfrentando o medo da morte}

Diante do diagnóstico de câncer, os sentimentos de desesperança, de angústia e medo são comuns. Conforme evidenciamos nos discursos a seguir, há a necessidade de um reforço no suporte social dessas pacientes.

Deus é quem sabe o dia que a gente vai morrer, mas acho que não saio dessa não, dizem que quando mexe, morre mais rápido (Gardênia).
Assim, esta mulher revela a vulnerabilidade emocional, ante a possibilidade da morte decorrente de uma doença como 0 câncer, marcado por estigmas. Esta vulnerabilidade é ainda mais acentuada no câncer de mama, gerador de mutilações passíveis de alterar a imagem corporal, que levam, na maioria das vezes, a sentimentos de ansiedade, depressão e medo perante a finitude da vida. Causa ainda, descredibilidade nos tratamentos e numa possível luta pela vida.

Atualmente, muitos são os casos de sobrevida. É fundamental, então, compreendermos a experiência de se viver com o câncer de mama, pois a incerteza é presença constante nas vidas dessas mulheres e se manifesta, geralmente, pelo medo de recorrência da doença ${ }^{15}$. Ao tomar conhecimento de uma ameaça real à vida, o indivíduo nega e tenta não acreditar na veracidade do fato. 0 medo e a proximidade da morte levam a pessoa a manifestar diversos sentimentos, os quais podem ou não ser superados ${ }^{15}$.

É necessário, portanto, um suporte social, espiritual e psicológico. Muitas mulheres encontram este suporte na familia.

Cheguei em casa e desabei em lágrimas para o meu marido, que me apoiou e me disse que estava do meu lado. (Margarida)

0 apoio familiar é essencial na superação de conflitos como medo, confusão, ansiedade e depressão e pode propiciar à mulher formas opcionais de viver, mesmo com limitações ${ }^{1}$.

\section{Nem tudo está perdido}

Na tentativa de entender o motivo do seu câncer, e para se adaptar à situação e conviver com a doença, a mulher vivencia complexos sentimentos. A maioria delas, porém, descobre-se forte, utilizando-se de estratégias como a fé e a solidariedade. Apesar do impacto, a mulher começa a buscar novos propósitos de vida, apoiada em novas esperanças. As estratégias de enfrentamento variam e podem ser focalizadas na emoção, quando buscam fazer com que a pessoa se perceba melhor mediante a redução do desconfor to emocional sentido como negação da realidade (evitando qualquer referência ao problema, negando sua existência). Outras estratégias são o afastamento, a minimização (com vistas a reduzir a importância da doença) e a atenção seletiva.

A nosso ver, a mudança na forma de negação da realidade ocorre quando a pessoa altera o significado de uma situação estressante para manter a esperança, negar os fatos $\mathrm{e}$ implicações, recusar-se a aceitar o pior ou a agir, como se 0 ocorrido fosse irrelevante. 0 enfrentamento focalizado no problema centraliza-se em defini-lo, criar soluções alternativas visando o controle do problema gerador do desconforto. Agir implica modificar os estressores ambientais, mudar as expectativas em relação às próprias metas, encontrar canais alternativos de gratificação e aprender novas habilidades e comportamento ${ }^{10}$. 
[...]Mas se eu tiver uma nova chance, agora eu vou cuidar mais de mim, vai ser como nascer de novo, se possível com data de aniversário e tudo (Margarida).

No presente estudo identificamos significados após o impacto do diagnóstico e aceitação do novo "self" em que a mulher começa a buscar melhoras na qualidade de vida. A doença induz à consciência da necessidade de modificar determinados hábitos; o processo de adoecer leva a mulher a uma valorização da vida e do cuidado consigo mesma, priorizando o seu desenvolvimento pessoal ${ }^{11}$.

O câncer parece uma sentença de morte, um aviso prévio, mas pode ser uma chance de refazer sua vida independentemente de quanto tempo ela dure. (Papoula)

A experiência de vivenciar o câncer não significa obrigatoriamente um aviso de morte, pode constituir-se no ponto de mutação. Quase todas as pessoas constroem suas vidas de maneira muito racional, evitam olhar para trás e refletir sobre as condutas e compreender o seu "eu", desligando-se da forma como estabelecem suas relações com o ambiente e os semelhantes. No entanto, ao se depararem com uma doença grave, de estigma incurável como o câncer, elas são induzidas a buscar 0 autoconhecimento, a avaliar sua postura ante as situações da vida, a resgatar alguns valores e princípios muitas vezes esquecidos em função dos interesses materialistas que nortearam suas vidas até aquele momento ${ }^{10}$.

Desse modo, ao determinar novas perspectivas de vida, a mulher ultrapassa os limites da doença. Reintegra, portanto, sua identidade dentro de um novo conceito de si mesma, formando e reformulando o novo "self", ou seja, aceitando-se como uma mulher portadora de câncer de mama.

Vejo a doença como um aviso de Deus, para a gente valorizar melhor o que tem, uma familia, amigos, é como se fosse para a gente acordar e viver melhor" (Dália).

0 enfrentamento do câncer de mama surge para cada mulher a partir das suas concepções pessoais e sentimentos sobre a doença. Assim, o "self" de cada uma se manifesta na construção de novas metas para a sua vida a partir do câncer.

Portanto, o enfermeiro deve reconhecer até que ponto esses sentimentos podem interferir no tratamento dessas mulheres, para que essas emoções não venham a acarretar danos à saúde emocional ${ }^{16}$

\section{CONSIDERAÇÕES FINAIS}

De modo geral, para a mulher, o impacto do diagnóstico é centrado em interações, nas visões de mundo e de si mesma, que ela construiu ao longo da vida. Mas a confirmação de uma doença grave e estigmatizada como o câncer de mama é fator desencadeante de sentimentos denotadores do sofrimento de se descobrir com tal doença. Neste estudo, o referencial teóricometodológico adotado permitiu compreender que vivenciar o câncer de mama é representado pelas mulheres por medos e reações emocionais complexas. Angústia, desespero e dor associam-se ao medo da mutilação, da perda da integridade física e emocional decorrentes da descoberta do câncer de mama.

Os depoimentos deixaram transparecer que o câncer de mama surge como uma ameaça à vida e à integridade física $e$ emocional das mulheres. Entretanto, o impacto desse momento é derivado, parcialmente, do significado do câncer para as mulheres e da forma como elas passam a agir diante desse significado.

Ao receber o diagnóstico de câncer de mama, a mulher vivencia a expectativa de um futuro incerto, de um caminho de grandes dificuldades, e também o medo da morte e mutilação. Portanto, a mulher convive com sentimentos contraditórios e intensos, nos quais o medo, a raiva, a incerteza e até mesmo a aceitação passam a fazer parte do seu dia-a-dia. 0 modo como esse diagnóstico influencia a conduta da mulher em parte é construído ao longo de suas experiências e do significado que a doença tem para ela.

Os depoimentos evidenciaram as dificuldades e medos das mulheres, prevalecendo a busca por uma nova percepção de si mesmas, agora como mulheres que têm câncer. De acordo com a perspectiva interacionista, nesse momento, a mulher passa a ver um novo "self", no contexto da doença, ao identificar mudanças em seu "eu", quando comparado ao que ela era antes do diagnóstico; ou seja, a ação é também um fruto das vivências. Do contexto, revela-se a importância do suporte social, do estabelecimento de novas perspectivas, da contribuição para um ajuste social após o diagnóstico. Ao perceber esse apoio a mulher pode tornar-se forte e capaz de buscar uma nova reintegração do "self"; pode, principalmente, encontrar uma melhor qualidade de vida, um começar de novo, apesar do câncer.

\section{Referências}

1.Fernandes AFC, Mamede MV. Câncer de mama: mulheres que sobreviveram. Fortaleza (CE): Ed UFC; 2003.

2.Ministério da Saúde (BR). Instituto Nacional de Câncer- INCA. Coordenação de Programas de Controle do Câncer/Pró-ONCO. Câncer no Brasil: dados de registro de base populacional. Rio de Janeiro (RJ); 2003.

3.Ferreira MLSM, Mamede MV. Representação do corpo na relação consigo mesma após mastectomia. Rev Latino-am Enfermagem 2003 maio/jun; 11(3): 299-304.

4.Melo EM. Processo adaptativo da família frente à mastectomia [dissertação de mestrado]. Fortaleza (CE): Programa de Pósgraduação em Enfermagem/Departamento de Enfermagem/UFC; 2001.

5. Sousa AS. Câncer de mama: representações e medos [monografia de graduação]. Fortaleza(CE): Departamento de Enfermagem/UFC; 2000.

6. Charon JM. Symbolic interactionism: an introduction, an interpretation, an integration. $7^{\mathrm{a}}$ ed. New Jersey (USA): Prentice Hall; 2001. 
7. Blumer H. Symbolic interactionism: perspective and method. New Jersey (USA): Prentice Hall; 1969.

8.Minayo MCS. Pesquisa social: teoria, método e criatividade. Rio de Janeiro (RJ): Vozes; 2002.

9. Rzeznik C, Agnol CMD. (Re) descobrindo a vida apesar do câncer. Rev Gaucha Enferm 2000; 21 (n.esp): 84-100.

10-Mamede MV. Fernandes AFC. 0 surgimento do câncer de mama na visão de um grupo de mulheres mastectomizadas. Texto\&Contexto Enferm 2004 jan/mar; 13(1): 35-40.

11.Fernandes AFC. 0 cotidiano da mulher com câncer de mama. Fortaleza (CE): Fundação Cearense de Pesquisa e Cultura; 1997.

12. Leshan L. 0 câncer como ponto de mutação: um manual para pessoas com câncer, seus familiares e profissionais de saúde. São Paulo (SP): Summus; 1992.
13. Caliri MHL. Câncer de mama: a experiência de um grupo de mulheres. Rev Bras Cancerol 1998; 44(3): 239-47.

14.Almeida AM, Mamede MV, Panobianco MS, Prado MAS, Clapis MJ. Construindo o significado da recorrência da doença: a experiência de mulheres com câncer de mama. Rev Latino-am Enfermagem 2001 set/out; 9(5): 63-9.

15. Kubler-Ross E. Sobre a morte e o morrer. São Paulo (SP): Martins Fontes; 1989.

16. Carvalho ALS, Leitão NMA, Bezerra SJS, Barros SKS, Nobre RNS, Pinheiro AKB. Sentimentos de mulheres em tratamento para papillomavirus humano. Esc Anna Nery Rev Enferm 2007 jun; 11 (2): 248-53. 